\title{
Integrated Optics - Sensors, Sensing Structures and Methods
}

\author{
Tadeusz Pustelny* \\ Department of Optoelectronics, Silesian University of Technology, 2A Akademicka St., 44-100 Gliwice, \\ Poland
}

Received June 30, 2016; accepted June 30, 2016; published June 30, 2016

\begin{abstract}
The current issue of the Photonics Letters of Poland contains 7 selected paper presented during the $11^{\text {th }}$ Integrated Optics Sensors, Sensing Structures and Methods Conference, which was held form February $28^{\text {th }}$ to March $4^{\text {th }}$ in Szczyrk, Poland. The remaining 3 papers included in this issue are regular contributions.
\end{abstract}

Current issue of Photonic Letters of Poland is mainly dedicated to the Integrated Optics - Sensors, Sensing Structures and Methods (IOS) Conference.

The IOS Conference is an international scientific forum devoted to photonics, nanotechnology and modern metrology. It is organized annually and in 2016 it was held for the eleventh time. Specifically, IOS 2016 Conference took place from $29^{\text {th }}$ of February to $4^{\text {th }}$ of March in META hotel located in Szczyrk, in the Beskidy Mountains in South Poland, in real winter scenery.

More than 60 scientists, mainly from Poland but also from Australia, Slovakia, Germany and Czech Republic participated in IOS 2016 Conference.

The main organizer of the $11^{\text {th }}$ IOS Conference was the Photonics Society of Poland in cooperation with SPIE. The technical co-organizers of the Conference were the Upper Silesian Division of the Polish Acoustical Society and the Optoelectronic Department at the Silesian University of Technology in Gliwice (Poland). As it takes place for many years, also this time the IOS Conference has been promoted by the Committee of Electronics and Telecommunication of the Polish Academy of Sciences.

It is worth to underline that more than fifty oral lectures have been delivered in eight scientific sessions and nearly thirty posters have been presented during the IOS 2016 Conference. Specifically, scientific results and experiences in the field of technology and theoretical analysis of optoelectronic sensors and practical applications of sensing structures and systems, as well as new methods in the field of modern metrology, have been shown.

The first paper (X. Chen et al.) demonstrates all-optical fabrication of the quasi-phase matched structures based on ferroelectric domain inversion in $\mathrm{LiNbO}_{3}$ wafers and

* E-mail: Tadeusz.Pustelny@ polsl.pl waveguides using femtosecond infrared pulses, allowing thus for the conversion efficiency of the second harmonic generation as high as $17.45 \%$ achieved in a channel waveguide. The second paper (Filipkowski et al.) is devoted to the world-smallest fiber-GRIN lens system, which is perfectly suited for optofluidic sensor applications and is made with a novel technology of nanostructed optics. The contribution by M. Jankowski et al. presents selected works focused on research aspects concerning accelerator control systems for high energy physics, nuclear fusion based new energy sources and design of integrated electronics for space applications. The next two papers are devoted to the supercontinuum generation. Specifically, the paper by Holdynski et al. deals with three-fold symmetry microstructured fibers, while in the paper by Jozwik et al. experimental analysis of the supercontinuum generation obtained in highly birefringent and highly nonlinear dual-mode fiber are presented. In the sixth conference paper (K. Murawski et al.) results of the studies on the distance range visual measurement in the new Depth From Defocus method are presented. This method has been developed to determine the shape of a flaccid diaphragm used in the Ventricular Assist Device. The last contribution by Rutkowska et al. a wedge-cell method is presented and then it is compared with other methods and techniques that can be used to determine refractive indices of liquid crystalline material.

In conclusion, we would like to express our gratitude to all participants and we are looking forward to meet in Szczyrk next winter during upcoming IOS 2017. 